7. Lewander WJ, Lacouture PG. Office management of acute pediatric poisoning. Pediatr Emerg Care 1989; 5: 262-272.

8. Kullig $\mathrm{K}$, Duffy $\mathrm{KP}$, Lunden $\mathrm{CH}$ et al. Toxic effects of methanol, ethylene glycol and isoproply alcohol. Top Emerg Med 1984; 6: 14.

9. Anas N, Namasonthi V, Ginsburg CM. Criteria for hospitalizing children who have ingested products containing hydrocarbons. JAMA 1981; 246: 840-843.

10. Berg KJ. Acute acetyl salicylic acid poisoning : treatment with forced alkaline diuresis and diuretras. Eur J Clin Phamacol 1977; 12 : 111-116.

11. Morgan DP. Recognition and management of pesticide poisonings. 3rd edn. Washington DC. VS Environmental Protection Agency, 1982.

12. Rumack BH, Peterson RC, Koch GC et al. Acetaminophen overdose. 662 cases with evaluation of oral acetylcysteine treatment. Arch Intem Med 1981; 1141 : 380-385.

13. Crome P. Antidepressant overdosage. Drugs 1982; 23 : 431-435.

\title{
THE INDICATOR OF STAFFING NEED (ISN) SYSTEM
}

The ISN system uses formulae to calculate the requirement for any particular category of health worker in the general form : $n=v 1 \times w 1+v 2 \times w 2+v 3 \times w 3$ etc

where $\mathbf{n}=$ the number of staff required, $\mathbf{v}=\mathbf{a}$ volume measure of work-load, $w=a$ weight to be attached to that unit of work-load, and $p=$ a productivity standard.

To take an example, the method was applied to find how many nurses were required to staff a district hospital. The volume measures chosen were inpatient days and outpatient attendances (all types). After some trial with alternatives, a weight of 12 was assigned to an inpatient day, relative to a weight of 1 for an outpatient attendance. Lastly, a productivity standard of 10200 wcighted units per year was adopted. When applied to a district hospital which in 1986 had recorded 85534 inpatient days and 55843 outpatient attendances, the formula yielded a requirement for 106 nurses: $n=85534 \times 12+55843$

10200

$$
=106
$$

Abstracted from:

World Health Forum 1990; Vol. 11: No. 4, 399. 